\title{
TENSÕES E CONTRADIÇÕES DO CONCEITO DE ORGANIZAÇÃO APLICADO À UNIVERSIDADE: O CASO DA CRIAÇÃO DA USP-LESTE ${ }^{1}$
}

\author{
Sylvia Gemignani Garcia* \\ Maria Caramez Carlotto**
}

Recebido: 10 mar. 2012

Aprovado: 26 mar. 2012

* Departamento de Sociologia da Faculdade de Filosofia, Letras e Ciências Humanas da Universidade de São Paulo (DS-FFLCH-USP). São Paulo, SP, Brasil.

Contato com a autora: sylgemig@usp.br

** Programa de Pós-Graduação em Sociologia da Faculdade de Filosofia, Letras e Ciências Humanas da Universidade de São Paulo (PPGS-FFLCH-USP). São Paulo, SP, Brasil.

Contato com a autora: mariacarlotto@usp.br

Resumo: O estabelecimento de um novo campus da Universidade de São Paulo em uma área periférica da cidade de São Paulo é analisada neste artigo como um caso empírico das tensões entre a concepção organizacional e as particularidades institucionais da universidade, revelando as contradições internas ao conceito de "organização" quando aplicado às universidades. Com base nessa análise, explicamos os conflitos que opuseram professores e coordenadores do projeto USP-Leste durante a implementação da escola criada para promover o desenvolvimento socioeconômico local. O caso também mostra a influência da cultura política brasileira sobre o processo de mudança acadêmica que se desenrola em nível global.

Palavras-chave: Universidade. Teoria das organizações. Gestão universitária. Cultura política. Reforma da educação superior.

\section{TENSIONS AND CONTRADICTIONS OF THE CONCEPT OF ORGANIZATION AS APPLIED TO UNIVERSITIES: THE CASE OF USP-LESTE}

Abstract: The establishment of a new campus by the University of São Paulo in a peripheral area of São Paulo city, Brazil, is analyzed as an empirical case of the tensions between the organizational conception and the institutional particularities of the university, revealing the internal contradictions of the concept of 'organization' as applied to universities. Based on this, we explain the conflicts that opposed university professors and leaders during the implementation of a school created to promote the local socioeconomic development. The case also shows the influence of the Brazilian political culture on shaping the globalizing process of academic change.

Key words: University. Organizacional theory. University management. Reform of higher education.

\section{INTRODUÇÃO}

Um dos maiores desafios para a sociologia da educação contemporânea é compreender a natureza das transformações que incidem atualmente sobre as universidades em todo o mundo, projetando uma redefinição de seu papel e funcionamento institucional. Nesse contexto, muitos estudos, sobretudo na Europa e nos Estados Unidos, vêm apontando para a influência da "teoria organizacio-

\footnotetext{
1 Esta pesquisa contou com o apoio da Fundação de Amparo à Pesquisa do Estado de São Paulo (FAPESP).
} 
nal" nos projetos de reforma das universidades. Brunsson e Sahlin-Andersson (2000), por exemplo, ao descreverem a reforma do setor público, incluindo as universidades, falam de um esforço para "construir organizações". Hedmo et al (2006), seguindo as categorias de Powell e DiMaggio (1991), apontam a emergência de um campo organizacional para o ensino superior. Krücken e Meier (2006) são mais diretos e falam da transformação das universidades em organizações. O mesmo tipo de questão orienta as análises de Meyer et al (2006), Drori et al (2006), Bleiklie e Kogan (2007) e Musselin (2006). Em todos esses textos, um diagnóstico comum: a agenda globalizante de modernização das universidades propõe uma completa redefinição das estruturas, normas e práticas acadêmicas nos termos de um ideal geral de "organização".

Esses estudos mostram como o conceito de organização, destacado das experiências contextualizadas que lhe deram origem, é generalizado em um conjunto de fórmulas que estariam disponíveis para uso em qualquer configuração institucional e nacional. Baseado nessa generalização questionável, o novo paradigma da gestão pública sustenta que a modernização institucional requer uma gestão centralizada e hierarquizada, capaz de exercer controle sobre as atividades e condutas de todos os membros de qualquer instituição, inclusive da universidade. De acordo com essa visão, a gestão organizacional das universidades levará, certamente, a resultados mais eficientes, em especial, em termos de expansão e aprimoramento de suas funções socioeconômicas.

As mudanças na administração de empresas que reagem à crise econômica da década de 1970 induzem o fortalecimento e a sistematização das práticas administrativas que se cientificizam progressivamente, formalizando conceitos, modelos e instrumentos. Configurada como teoria organizacional, ela passa a competir com as ciências sociais em torno da descrição coerente e adequada à realidade empírica dos processos de ação coletiva no interior das instituições. Não é por acaso, portanto, que certas vertentes sociológicas da teoria neo-institucionalista retomam para si o debate em torno da dinâmica institucional na modernidade contemporânea, repondo-o no quadro mais amplo - tradicional ao campo dos estudos das ciências sociais - de uma teoria sociológica das práticas.

O estudo da concepção e implementação de um campus da USP na zona leste de São Paulo (USP-Leste) ${ }^{2}$ como um caso de engajamento social da universidade permite uma reflexão crítica acerca da adequação empírica e dos resultados do conceito de organização, quando aplicado às universidades. Para isso, primeiro, expomos o enfoque sociológico que adotamos para abordar as

2 A análise se baseia em 15 entrevistas realizadas pelas autoras, atas do Conselho Universitário, relatórios e pareceres da USP e documentos acadêmicos e administrativos da USP-Leste. 
mudanças acadêmicas atuais. Em seguida, descrevemos os aspectos essenciais da criação e implementação da USP-Leste para, na sequência, discutir os conflitos surgidos entre professores e gestores no período inicial de funcionamento do novo campus, que delimitamos como segundo período da implementação. Nessa análise, a criação da USP-Leste é reconstruída como um caso empírico das contradições entre o conceito de organização e as particularidades institucionais da universidade que, por sua vez, revelam as contradições internas ao conceito idealizado de organização. Em consequência, a conclusão aponta para a necessidade teórica e prática da crítica do uso da noção de organização para guiar as mudanças orientadas para a promoção das relações entre a universidade e seus contextos sociais locais.

\section{COMO ENTENDER A DINÂMICA DA MUDANÇA ACADÊMICA CONTEMPORÂNEA?}

As mudanças que hoje afetam as universidades em todo o mundo são largamente orientadas por um pensamento organizacional que assume que todas as instituições - incluindo, como qualquer outra, as universidades - são melhor entendidas e administradas quando vistas e compreendidas como organizações (BRUNSSON; SAHLIN-ANDERSSON, 2000; KRÜCKEN; MEIER, 2006; MUSSELIN, 2006). A “organização" torna-se, assim, um conceito geral capaz de descrever quase todas as formas institucionalizadas da atividade humana, em qualquer tempo e lugar. Da perspectiva dessa suposição abstrata, as mudanças acadêmicas atuais são processos quase-naturais de adaptação que promovem, necessariamente, a eficiência técnica e social da instituição. Assim, a universidade deve evoluir para a forma da organização moderna, eficiente e responsável, superando a forma da comunidade corporativa e ineficiente que se autogoverna visando atingir objetivos autodefinidos.

Esse conceito de organização moderna, aplicado às universidades, pode ser definido por quatro características básicas.

A primeira é que ele se baseia em elementos relativamente autonômos, que podem circular separadamente uns dos outros, como "filamentos independentes" (independent strings) (BRUNSSON; SAHLIN-ANDERSSON, 2000; KRÜCKEN; MEIER, 2006). Além disso, o conceito pode funcionar como uma matriz de referência tácita, que estimula a redefinição de características históricas da universidade como problemas para os quais as mudanças organizacionais são a solução. A independência relativa dos elementos implica que uma mudança tende a induzir a adoção de outras, o que explica tanto a 
alta velocidade com que as mudanças se implantam, quanto as dificuldades de opor-se a elas: uma vez que o primeiro elemento aparece como uma mudança pontual, os seguintes vão emergindo como consequências naturais das decisões anteriormente tomadas.

A segunda característica - igualmente devida a seu alto nível de abstração - é que o conceito de organização moderna concebe a universidade desvinculada de seu contexto local e dos padrões tradicionais da profissão acadêmica. Convertida em organizações, na teoria ou na prática, as universidades são inseridas em um circuito global de competição institucional, em um processo que Walter Powell e Paul DiMaggio descrevem como a construção de um campo organizacional das universidades (POWELL; DIMAGGIO, 1991). No interior desse campo, elas são orientadas para a criação de uma identidade institucional forte, com poucos objetivos muito bem definidos, para além da interferência, seja do estado nacional, seja das profissões acadêmicas (KRÜCKEN et al, 2006). Essa nova forma que reivindica a identidade de autonomia universitária - sendo de fato mais um tipo organizacional de autonomia - inspira-se largamente na ideia da grande corporação econômica moderna, fortemente baseada em uma delimitação estrita entre um "dentro" - a empresa e seu "time", "que veste a camisa" - e um "fora" - o ambiente e todas as outras formas de "externalidades". No caso da universidade, o fortalecimento das fronteiras institucionais significa ampliar e aprofundar o controle das variadas formas de ligação entre a universidade e o que quer que seja em certo momento considerado como 'seu entorno' - a sociedade, as empresas nacionais, as comunidades locais, os usuários dos campi que não são membros da instituição etc.

A terceira característica da organização moderna é a responsabilidade institucional (accountability), contrapartida da autonomia organizacional. Entre os processos que apontam nessa direção, sobressaem: (1) a crescente importância das certificações e rankings internacionais; (2) a racionalização das atividades de ensino e pesquisa; (3) o desenvolvimento de técnicas e instrumentos de controle e coordenação desses processos; (4) a ideia de que a universidade deve ter missões claras, incluindo entre elas uma missão social e (5) o valor atribuído ao marketing institucional para a promoção do sucesso das missões.

Para atender às exigências da responsabilidade social, espera-se que as universidades desenvolvam estruturas formais. Assim o quarto componente da ideia organizacional são as instâncias estruturais centralizadas e hierarquizadas para coordenação e controle das decisões e das ações dos membros individuais. Esse aspecto explica a emergência da "onda da gestão" ("managerialism wave"), que se espraia sobre as profissões acadêmicas e o estado nacional: a nova ênfase 
no nível organizacional abre espaço para que os gestores profissionais - suas visões, técnicas e instrumentos - ocupem os lugares das lideranças acadêmicas (MUSSELIN, 2006).

Essas quatro características expressam claramente que o ideal moderno de organização, aplicado à universidade, tende a redefini-la como uma instituição geral e abstrata, que pode ser exitosamente modernizada por reformas organizacionais.

Muito diverso é o entendimento sociológico da mudança contemporânea da universidade que adotamos aqui. Primeiro, o conceito de organização opera uma excessiva e problemática generalização, parcialmente baseada em um equívoco conceitual: o esquecimento das especificidades históricas e institucionais das atividades humanas organizadas, que estão na base do entendimento sociológico da ação. A falha, por sua vez, conduz ao erro metodológico de uma universalização pouco apropriada de um conjunto restrito de casos, considerados exemplares da mudança organizacional.

A partir de uma perspectiva crítica dessa teoria organizacional é possível afirmar que o processo de mudança da universidade só pode ser compreendido se consideramos os complexos arranjos gerados por sua difusão, em diferentes contextos nacionais e institucionais, vistos como dimensões enraizadas histórica e culturalmente (FRANK; MEYER, 2007; KRÜCKEN; MEIER, 2006; KRÜCKEN et al, 2006).

A atenção ao arranjo específico também importa para que se possa considerar o conjunto de tendências globais mais como construções sociais do que como fatos inexoráveis. Incorporando os principais insights da teoria neo-institucionalista, pode-se interpretar as mudanças recentes nas estruturas e objetivos das universidades como um movimento orientado para a conversão da universidade em organização, que vem gerando diferentes arranjos em situações locais e institucionais variadas (BRUNSSON; SAHLIN-ANDERSSON, 2000; KRÜCKEN; MEIER, 2006; MUSSELIN, 2006). Trata-se de investigar os modos pelos quais as tendências globalizantes convergentes geram a heterogeneidade de resultados que se observa empiricamente em diversos lugares do mundo.

No que se refere à especificidade institucional da universidade, é preciso considerar que as características das estruturas e práticas acadêmicas vinculam-se tanto à natureza particular de suas atividades quanto ao seu caráter historicamente enraizado. Ensinar e pesquisar são atividades que requerem pouca coordenação e cooperação, concedendo um grau relativamente alto de autonomia aos seus praticantes. Essa forte independência é alimentada por 
práticas históricas tais como, para um único exemplo, a prática da não-interferência mútua (MUSSELIN, 2006). Essa relativa independência acadêmica, historicamente gerada e controlada por um tipo de concorrência que obriga às regras do diálogo metódico e da crítica racional generalizada (BOURDIEU, 2007, p. 133), se expressa em sua característica institucional mais específica: ao contrário, por exemplo, da instituição corporativa, a universidade moderna distingue-se por incorporar objetivos variados e inclusive divergentes entre si (BEN-DAVID; ZLOCZOWER, 1962; SILVA, 1999). Além disso, o ensino e a pesquisa são, na expressão de Cristine Musselin, 'unclear technologies'. Não sendo possível estabelecer uma relação causal nítida entre tarefas específicas e resultados esperados, o trabalho intelectual apresenta resistência a sua formalização e segmentação em partes.

No que concerne ao governo acadêmico, a universidade pode ser descrita como uma instituição onde, historicamente, estruturas formais de controle das práticas tiveram pouca eficácia e as tarefas administrativas foram geridas por corpos colegiados em formas descentralizadas de auto-governo, fazendo das universidades o exemplo mais bem acabado das "anarquias organizadas", nas quais o governo interno distingue-se por formas fluidas de participação (COHEN et al, 1972; KRÜCKEN; MEIER, 2006). É esse o contexto que permite, por exemplo, que seus profissionais tenham uma relação institucional mais forte com as disciplinas em que se formaram do que com a universidade que os emprega.

Finalmente, a heterogeneidade que resulta da aplicação situada dos princípios organizacionais abstratos depende ainda do contexto nacional em que as mudanças acontecem. Como observam Krücken et al (2006), no processo de contextualização local das tendências globais, elementos de diferentes níveis podem se ligar de modos muito variados. Dessa forma, a cultura nacional pode colidir com certas tendências globalizantes, mas pode também reforçar alguns de seus elementos esquematizados.

\section{A CRIAÇÃO DA USP-LESTE}

\subsection{O Espaço Social}

A Universidade de São Paulo faz parte de um dos mais importantes polos do sistema científico brasileiro ${ }^{3}$. Junto com a Universidade Estadual Júlio de

3 Em 2000, a região Sudeste concentrava 66,1\% de docentes de ensino superior com doutorado; $64 \%$ dos cursos de mestrado; $80 \%$ dos de doutorado; $63 \%$ dos recursos do Conselho Nacional de Desenvolvimento Científico e Tecnológico $(\mathrm{CNPq}) ; 71 \%$ dos investimentos sem retorno da Financiadora de Estudos e Projetos (FINEP) do Ministério de Ciência e Tecnologia; e 80\% das empresas com atividade em P\&D 
Mesquita (UNESP) e a Universidade Estadual de Campinas (UNICAMP), as "públicas paulistas" concentravam, em 2008, 15\% dos grupos de pesquisa do Brasi $1^{4}$, sendo responsáveis por aproximadamente um terço dos doutorados concedidos no país (SCHWARTZMAN, 2007, p. 162). Parte de um contexto que a transcende, a USP ocupa nele um lugar especial, na posição da mais antiga referência nacional de autonomia universitária, articulando padrões institucionais específicos e excelência intelectual. Como se sabe, as missões estrangeiras que formaram a primeira geração de docentes da Universidade quando de sua fundação promoveram a implantação de procedimentos e padrões especificamente acadêmicos de organização, funcionamento e avaliação, revolucionando o ensino superior no país (CARDOSO, 1982; CANDIDO, 1984; MICELI, 1987; ARANTES, 1994).

No interior de um espaço social altamente estratificado, as disposições para a preservação desse padrão de produção de conhecimento erudito e especializado podem chocar-se com as demandas sociais de expansão do acesso, democratização da pesquisa e fortalecimento da extensão, nas quais amplos setores da universidade tendem a ver uma ameaça à qualidade e à autonomia da produção de conhecimento ${ }^{5}$.

E é justamente essa universidade de excelência, com padrões acadêmicos enraizados, que vai, no começo da década de 2000, propor a criação de um novo campus em uma região periférica da cidade, a zona leste (ZL) de São Paulo.

A zona leste foi, originalmente, uma área operário-industrial, circunscrita aos bairros laterais ao centro da cidade, que se desenvolveu em torno da linha férrea que acompanha, do século XIX até hoje, o leito do Rio Tietê. A partir dos anos 1950, à medida que a população foi crescendo, os limites urbanos da zona leste também se expandiram, formando novos bairros localizados no extremo leste, que passaram por uma "explosão demográfica" nos anos 1980, fazendo da região uma das mais populosas da cidade (SÃO PAULO, 2007, p. 14).

Esse grau de concentração urbana, alcançado nessa velocidade, só foi possível porque baseou-se em um padrão precário de ocupação do território. O exemplo mais explícito desse processo são as condições de habitação das periferias localizadas nos extremos de São Paulo, onde 3,4 milhões de pessoas vivem em "assentamentos precários", dos quais 1,6 milhões em "moradias

(SILVA, 2000, p. 63).

4 Dados do Diretório de Grupos do Conselho Nacional de Desenvolvimento Científico e Tecnológico (CNPq), disponíveis em: http://dgp.cnpq.br/censos/

5 Os idealizadores da USP-Leste tinham clareza da força dessa posição, como nota a pedagoga e líder do projeto: "O temor difundido é que ocorra, no ensino superior, o que ocorreu nos ensinos básico e médio, em que o processo de universalização do acesso levou a um desastroso rebaixamento de qualidade" (KRASILCHIK, 2008, p. 26). 
precárias localizadas em loteamentos irregulares", 1,2 milhões em favelas e 600 mil em cortiços (SÃO PAULO, 2007, p. 55). Nessas periferias encontra-se a maior parte dos domicílios com esquemas de abastecimento de água "não-recomendáveis sanitariamente" e com "formas nocivas de esgotamento sanitário e de destinação do lixo" (SÃO PAULO, 2007, p. 53-54).

$\mathrm{Na}$ zona leste, esse padrão precário de urbanização, não obstante a forte concentração populacional,é acompanhado por uma total escassez de serviços e aparelhos culturais. Considerando o total de 860 centros, galerias, museus, casas de shows e teatros da cidade, enquanto a zona oeste (ZO), onde se localiza o campus central da USP, concentra 374 aparelhos, a zona leste possui somente 52 , marcadamente concentrados nos bairros mais próximos do centro ${ }^{6}$.

Segundo os dados de níveis educacionais, em praticamente todos os distritos da zona leste, as taxas de analfabetismo ficam acima da média da cidade, exceção feita, novamente, aos bairros mais próximos do centro. Conforme uma dinâmica regional altamente hierarquizada, a taxa de analfabetismo aumenta à medida que se desloca para as periferias mais periféricas da cidade. A distância social aumenta se abarcamos os dados referentes aos três distritos que formam a zona oeste de São Paulo.

6 Dados do Departamento de Estatística e Produção de Informação, que não contemplam os Centros Educacionais Unificados (CEUs), complexos educacionais, esportivos e culturais instalados nas regiões periféricas da cidade de São Paulo a partir de 2003.

Mais informações: http://infocidade.prefeitura.sp.gov.br/ 
Tabela 1 - Taxa de analfabetismo e analfabetismo funcional da população com 15 anos ou mais (\% da população) para a Cidade de São Paulo e os Distritos da Zona Leste (2000)

\begin{tabular}{lcc} 
& $\begin{array}{l}\text { Taxa de } \\
\text { analfabetismo }\end{array}$ & $\begin{array}{l}\text { Taxa de } \\
\text { analfabetismo } \\
\text { funcional }\end{array}$ \\
\hline Município de São Paulo [total] & $\mathbf{4 , 5 0 \%}$ & $\mathbf{9 , 7 0 \%}$ \\
\hline Zona Leste (bairros próximos ao centro) & & $7,00 \%$ \\
Mooca/ Brás/ Tatuapé/ Pari/ Belém/ Água Rasa & $2,30 \%$ & $8,80 \%$ \\
Aricanduva/Formosa/ Carrão & $3,30 \%$ & $8,60 \%$ \\
Penha/ Arthur Alvim/ Cangaíba/Vila Matilde & $3,50 \%$ & $10,50 \%$ \\
Zona Leste (bairros do extremo leste) & & $10,20 \%$ \\
Vila Prudente/ Sapobemba/ São Lucas & $4,80 \%$ & $10,00 \%$ \\
Ermelino Matarazzo/ Ponte Rasa & $4,80 \%$ & $13,60 \%$ \\
Itaquera/Cidade Líder/José Bonifácio/Pq do Carmo & $4,60 \%$ & $12,40 \%$ \\
Itaim Paulista/ Vila Curuça & $6,40 \%$ & $12,30 \%$ \\
São Miguel/Jd Helena/ Vila Jacuí & $6,80 \%$ & $11,20 \%$ \\
São Mateus/ Iguatemi/São Rafael & $5,90 \%$ & $13,30 \%$ \\
Cidade Tiradentes & $5,20 \%$ & $3,3 \%$ \\
Guaianazes/ Lajeado & $7,50 \%$ & $8,90 \%$ \\
\hline Zona Oeste & & $5,6 \%$ \\
Butantã & $4,0 \%$ & \\
Lapa & $2,2 \%$ & \\
Pinheiros & $0,9 \%$ & \\
\hline
\end{tabular}

Fonte: Secretaria Municipal de Desenvolvimento Urbano/SMDU - Departamento de Estatística e Produção de informação/Dipro, a partir de dados do Censo IBGE 2000. Disponível em: <http://infocidade. prefeitura.sp.gov.br/>

Elaboração: própria.

No outro extremo, consideramos o percentual da população com ensino superior completo. Em todos os distritos do extremo leste da cidade, o percentual dos moradores com mais de 24 anos de idade com ensino superior completo fica bem abaixo da média da cidade de São Paulo e muito abaixo dos bairros nobres da zona oeste: 
Tabela 2 - Percentual da população com ensino superior completo em relação à população adulta (24 anos ou mais) por agregado de distritos (2007)

\begin{tabular}{|c|c|c|c|}
\hline & $\begin{array}{l}\text { População } \\
\text { total } \\
\text { ADULTA }\end{array}$ & $\begin{array}{l}\text { Com ensino } \\
\text { superior } \\
\text { completo }\end{array}$ & $\begin{array}{l}\text { Percentual } \\
\text { da população } \\
\text { ADULTA com } \\
\text { ES completo }\end{array}$ \\
\hline Município de São Paulo [total] & 6. 543. 671 & 1. 311.255 & $20,03 \%$ \\
\hline \multicolumn{4}{|l|}{ Zona Leste } \\
\hline $\begin{array}{l}\text { Moóca/ Brás/ Tatuapé/ Pari/ Belém/ } \\
\text { Água Rasa }\end{array}$ & 206. 713 & 57.706 & $28,00 \%$ \\
\hline Aricanduva/Formosa/ Carrão & 166. 974 & 33. 627 & $20,13 \%$ \\
\hline $\begin{array}{l}\text { Penha/ Arthur Alvim/ Cangaíba/Vila } \\
\text { Matilde }\end{array}$ & 298. 369 & 53. 053 & $17,78 \%$ \\
\hline Ermelino Matarazzo/ Ponte Rasa & 122. 767 & 16. 886 & $13,75 \%$ \\
\hline Vila Prudente/ Sapobemba/ São Lucas & 319. 653 & 39. 129 & $12,24 \%$ \\
\hline $\begin{array}{l}\text { Itaquera/Cidade Líder/José Bonifácio/ } \\
\text { Pq do Carmo }\end{array}$ & 301.613 & 28. 339 & $9,40 \%$ \\
\hline Itaim Paulista/ Vila Curuça & 214. 490 & 13. 180 & $6,14 \%$ \\
\hline São Miguel/Jd Helena/ Vila Jacuí & 219. 272 & 13145 & $6,00 \%$ \\
\hline São Mateus/ Iguatemi/São Rafael & 232. 178 & 12112 & $5,27 \%$ \\
\hline Cidade Tiradentes & 111.964 & 5895 & $5,26 \%$ \\
\hline Guaianazes/ Lajeado & 151. 616 & 5400 & $3,56 \%$ \\
\hline \multicolumn{4}{|l|}{ Zona Oeste } \\
\hline Butantã / Morumbi & 81.871 & 27.934 & $34,11 \%$ \\
\hline $\begin{array}{l}\text { Lapa/Barra Funda/ Perdizes/Vila } \\
\text { Leopoldina/Jaguaré }\end{array}$ & 256.427 & 86.341 & $33,67 \%$ \\
\hline Pinheiros/ Itaim Bibi/Jd. Paulista & 236.630 & 121.794 & $51,47 \%$ \\
\hline
\end{tabular}

Fonte: Secretaria Municipal de Desenvolvimento Urbano/SMDU - Departamento de Estatística e Produção de informação/Dipro, a partir de dados do Censo IBGE 2000. Para o nível de instrução, Metrô/SP - Pesquisa Origem e Destino 2007. Ambos disponíveis em. http://infocidade.prefeitura.sp.gov.br/

Elaboração: própria.

Fruto de um padrão específico de desenvolvimento capitalista, pelo qual a atividade econômica central tende a reforçar a existência de círculos de pobreza e hierarquias rígidas de desigualdade (OLIVEIRA, 2003; COMIN, 2003), essas distâncias sociais são o referencial que situa o sentido de urgência de que se reveste o engajamento acadêmico no projeto de redução das desigualdades, 
através de programas de expansão de vagas, identificados como requisitos para a superação desse padrão perverso de desenvolvimento. Veremos como esse sentido de urgência legitimou o processo de concepção e criação do novo campus da USP, por outro lado estimulado pelas tendências globalizantes organizacionais, conferindo-lhe a velocidade e a centralização que, no período imediatamente posterior, de efetiva implementação do projeto, vão entrar em conflito com os padrões acadêmicos de professores formados em campos disciplinares bem estruturados.

\subsection{A USP na Zona Leste}

A pressão por expansão de vagas nas universidades públicas brasileiras não é algo recente (CUNHA, 2004; GUIMARÃES, 2002, 2003) mas, entre o final da década de 1990 e início da década de 2000, ela ganha contornos dramáticos, fruto de uma configuração social complexa. Em primeiro lugar, fortaleceu-se o diagnóstico de que a política de expansão do ensino superior que, desde a década de 1970, mas sobretudo a partir da de 1990, privilegiou a abertura de vagas no setor privado, tinha sido, em grande medida, equivocada: de um lado, porque a qualidade dos cursos no setor privado era considerada muito insuficiente; de outro, porque a cobrança de mensalidades e a ausência de políticas de financiamento estudantil continuavam dificultando o acesso de camadas mais pobres da população ao ensino superior. Em segundo lugar, a pressão por ampliação de vagas no ensino superior público intensificou-se, naquele momento, em função das políticas de expansão de matrículas e contra a repetência e a evasão, que foram adotadas, nos anos precedentes, no ensino público fundamental e médio. Essa expansão gerou uma situação paradoxal, em que o sistema público de ensino básico passou a formar grandes contingentes de alunos de baixa renda que nem conseguiam ingressar no ensino superior público, nem financiar os estudos no setor privado.

Um componente importante dessa crise foi o fortalecimento dos movimentos sociais que demandavam acesso ao ensino superior brasileiro, como o Movimento dos Sem Universidade, que surge em 2000 a partir da organização de cursinhos populares, do movimento Hip-Hop das periferias das grandes cidades, da Pastoral da Juventude da Igreja Católica e de outros movimentos de educação popular; e o Movimento Negro, que passa a reivindicar a implantação de ações afirmativas nas universidades públicas, através de ONGs como a Educafro (GUIMARÃES, 2003). Um dos focos desses movimentos na cidade, a zona leste vinha reivindicando maior acesso à educação desde 1970, inicialmente no 
nível básico mas, depois, também no ensino superior. O chamado Movimento de Educação da Zona Leste de São Paulo foi um dos promotores da ideia do educador Paulo Freire de construir uma Universidade do Trabalhador na zona leste de São Paulo ainda nos anos 1980, proposta que nunca se concretizou (GOMES, 2005). Essa demanda pela criação de uma universidade pública na zona leste continuou ao longo do anos 1990, sobretudo por intermédio de deputados estaduais que protocolavam, na Assembleia Legislativa Estadual, diferentes projetos que propunham a criação de uma universidade pública na região, sem que nenhum deles tivesse ido adiante (GOMES, 2005).

Finalmente, completam o quadro as diretrizes globalizantes de reforma universitária, incorporadas pelos agentes acadêmicos locais, que enfatizam as funções sociais da instituição, concebendo a expansão do acesso ao ensino superior no registro da responsabilidade social, como um engajamento direto com a formação para o mercado de trabalho e o desenvolvimento.

É nesse contexto que o Conselho de Reitores das Universidades Estaduais de São Paulo (CRUESP) - que reúne os dirigentes da USP, da UNESP e da UNICAMP - criou, em 2001, a Comissão Especial para a Expansão do Ensino nas Universidades Estaduais Paulistas, com o objetivo de "propor medidas voltadas à expansão de cursos e vagas" e manifestar-se "quanto à necessidade de criação de novas instituições de ensino superior no Estado" (CONSELHO DE REITORES DAS UNIVERSIDADES ESTADUAIS DE SÃO PAULO, 2001, p. 2). Como resultado, coube especificamente à USP a recomendação de abrir cursos tradicionais de pedagogia e licenciatura na zona leste da cidade de São Paulo.

Atendendo, em parte, às deliberações do CRUESP e, em parte, a pressões internas à USP, para que esta garantisse sua presença praticamente hegemônica na cidade de São Paulo - e, com isso, mantivesse inalterada a distribuição do orçamento estadual para o ensino superior -, o Reitor da USP criou, em 2002, uma Comissão - posteriormente denominada Comissão Central - para avaliar a "possibilidade e a conveniência" de instalação de uma unidade da USP na zona leste de São Paulo (GOMES, 2005, p. 30). Essa comissão transformou a proposta original de cursos tradicionais de educação em um grande projeto para um novo campus, que deveria incorporar inovações em todas as suas dimensões, acadêmica, pedagógica, administrativa e arquitetônica.

O reitor não apenas encampou a nova proposta, como decidiu que ele deveria ser implantada imediatamente e completada durante sua gestão na reitoria. Do mesmo modo, o governador concordou em financiar o projeto diretamente, com recursos extraordinários, contanto que ficasse pronto durante seu mandato no governo do estado. E, de fato, a construção começou em 2002 e em 2005 o 
campus começou a funcionar com 10 programas de graduação, 1020 vagas e 68 professores (GOMES, 2005).

O padrão de formação da Comissão Central já explicita as duas características marcantes do processo de implantação da USP-Leste: por um lado, a extrema centralização das decisões relativas ao projeto; por outro, a reprodução dos critérios acadêmicos de reconhecimento das competências especializadas. Do ponto de vista da centralização, partiu do reitor a decisão de que a coordenação geral do projeto caberia ao seu chefe de gabinete que, ao ocupar, simultaneamente, posições centrais na construção da nova unidade e na gestão reitoral, permitiria ao reitor controlar diretamente sua execução. Segundo esse mesmo critério, todos os membros da comissão central foram convidados diretamente pelo reitor para compô-la. Esse padrão de convites e nomeações diretas se manteve na criação das outras comissões ligadas ao projeto, como revelam as respostas dadas, por nossos entrevistados, à questão de como se deu o seu envolvimento com o projeto USP-Leste. Todos eles, sem exceção, relatam que foram chamados ou convidados a participar.

Esses convites e chamados, embora tenham partido inteiramente do reitor e, posteriormente, dos membros da Comissão Central, contemplavam, também, critérios de competência acadêmica e de especialização. Nesse sentido, foram convidados a participar da Comissão Central professores da USP que, notavelmente, possuíam competências específicas que poderiam ser mobilizadas na elaboração do projeto ${ }^{7}$. Esse padrão acadêmico de valorização da especialidade e da competência - que não excluiu o caráter centralizado das nomeações - se repõe em outros momentos da implantação da USP-Leste: na formação das duas comissões coordenadoras da implantação do projeto; na formação das comissões responsáveis pela elaboração dos currículos dos dez novos cursos de graduação; na realização dos concursos para a contratação dos professores para a nova escola.

No início, o projeto foi conduzido por duas comissões, compostas por professores também pessoalmente escolhidos pelo reitor, sob a coordenação geral de seu chefe de gabinete. No nível estrutural, a característica distintiva da proposta era a ausência de departamentos. No nível acadêmico, os cursos propostos claramente diferiam dos cursos tradicionais da USP, de orientação disciplinar. Uma perspectiva vocacional levou a propostas que incluíam: setores de potencial econômico (como o Curso de Lazer e Turismo); setores da saúde

7 Em sua composição final, a comissão agregou: duas pedagogas de forte expressão na universidade, um antropólogo envolvido com a discussão da carreira acadêmica e da estrutura departamental da universidade, um arquiteto, que elaboraria os primeiros croquis do novo campus, e um administrador de empresas. 
com potencial impacto social (como o Curso de Obstetriz ou o de Gerontologia); e temas relacionados à gestão (como, por exemplo, o Curso de Gestão Ambiental ou o de Gestão de Políticas Públicas). Em todos, o primeiro dos quatro anos de graduação é dedicado a um "ciclo básico", caracterizado por pedagogias ativas e temas interdisciplinares, com o objetivo de formar promovendo a cidadania e a solução local de problemas sociais (GOMES, 2005). Segundo seus proponentes, tal perfil distinguiria o caráter moderno do novo campus e sua conexão com as tendências internacionais da educação superior (KRASILCHIK, 2005).

O apoio da universidade ao projeto foi amplo. Pela primeira vez na história da USP, havia um consenso entre os dirigentes acerca da necessidade de uma atuação social pela expansão de vagas. Apesar da resistência de alguns setores no Conselho Universitário $(\mathrm{CO})$, ligada a críticas à rapidez da implantação e à incompletude e falta de discussão do projeto nos órgãos colegiados da universidade, pode-se dizer que, neste primeiro período, os obstáculos foram exitosamente superados pela convergência em torno de um duplo sentido de urgência - social e institucional - e pelo controle direto exercido pelo reitor sobre os processos de decisão do CO.

O início das atividades acadêmicas na USP-Leste revelou, entretanto, muitas outras fontes de conflito, iniciando o período de implementação. Trataremos do conflito que opôs professores a coordenadores e gestores em torno das concepções, estruturas e normas das atividades acadêmicas como um fenômeno que revela as tensões entre a orientação organizacional moderna e as práticas acadêmicas tradicionais.

Um componente fundamental dessa situação foi o processo de seleção dos novos professores que, seguindo os critérios acadêmicos tradicionais, contratou um corpo docente formado em sua maioria por jovens doutores socializados em competências disciplinares sob os padrões acadêmicos das universidades de pesquisa.

No nível estrutural, o fim dos departamentos criou um vácuo institucional que fez com que os diretores e coordenadores tivessem que arcar com quase todas, senão todas, as responsabilidades acadêmicas. Diante disso, os departamentos apareceram para certos professores como as instâncias adequadas para a direção e a administração na universidade. Mais ainda, para outros, os departamentos eram instâncias de decisão colegiada, cuja ausência implicava grande limitação das possibilidades de participação dos professores.

Outros impactos negativos atingiram as atividades de ensino, quando alguns coordenadores passaram a tentar definir o conteúdo dos programas das disciplinas para preservar a orientação pedagógica original. Isso gerou fortes 
conflitos, com os professores sentindo-se desautorizados em suas competências especializadas.

O uso de estratégias de gestão de recursos humanos - como a imersão em um hotel do interior por três dias para apresentação do projeto em palestras e apostilas - agravou os conflitos em torno do projeto original e muitos professores, inicialmente simpáticos ao projeto, acabaram por opor-se ao que um deles, em entrevista, designou de "ditadura pedagógica".

Finalmente, o descontentamento dos professores crescia enquanto a escola não fazia qualquer definição em relação às atividades de pesquisa, levando um conjunto significativo de docentes a buscarem inserção em outros programas de pós-graduação da USP.

Esse segundo estágio, marcado por problemas e conflitos, será seguido por uma fase de ajustamento que caracterizamos como o terceiro período de implantação do novo campus. Sob uma nova direção, e com muitos problemas para resolver, a escola se aproxima dos padrões tradicionais da universidade. As principais mudanças relacionam-se à pesquisa - hoje a escola tem 5 programas de pós-graduação - e ao estilo da liderança. $\mathrm{O}$ enfraquecimento do espírito missionário dos dois primeiros períodos foi acompanhado de uma diminuição dos conflitos, enquanto a escola foi passando a ser vista, cada vez mais, como uma unidade igual a todas as outras da USP.

\section{ANALISANDO A IMPLEMENTAÇÃO DA USP-LESTE}

Como entender esse processo de criação, implantação e implementação da USP-Leste, marcado primeiro pelo êxito e pelo consenso, em seguida por uma fase de conflitos e problemas, seguida por ajustamentos no período atual? Propomos explorá-lo como expressão do conflito entre o conceito de organização, que orienta tacitamente a reforma organizacional da universidade, e sua especificidade institucional, historicamente enraizada em práticas características de áreas disciplinares especializadas. Esse conflito revela a inadequação empírica do conceito de organização quando aplicado à universidade, mostrando como os elementos que o compõem, quando operacionalizados nesse contexto, tendem a colidir entre si, chocando-se um contra o outro.

\subsection{Tendências globalizantes no contexto político nacional}

Na década de 1990, a USP iniciou suas políticas de inclusão social seguindo um modelo que podemos denominar "de baixo para cima", ou seja, com 
o poder central da universidade apoiando iniciativas surgidas na comunidade acadêmica, como os cursinhos populares, e deixando espaço para as unidades decidirem sobre o ritmo da expansão. Depois, no entanto, a direção universitária passou a encampar grandes projetos centralizados, diretamente controlados pela reitoria, sendo o maior deles o projeto da USP-Leste. Essa mudança expressa a difusão do novo paradigma da gestão da reforma organizacional, enfatizando a importância da responsabilidade social da universidade e a necessidade de uma coordenação forte e centralizada.

A implementação da responsabilidade social iniciou-se nos anos 1990 na USP pela adoção de instrumentos de avaliação de ensino e pesquisa associados a pressões por produtividade acadêmica. Pode-se apontar entre esses instrumentos: (1) medida e avaliação do ensino e da pesquisa; (2) requisição de projetos pedagógicos e planos de metas regulares; (3) produção de novos arranjos institucionais para reduzir a o período de permanência dos estudantes em todos os níveis; (4) e o fortalecimento do marketing institucional como um meio de divulgar a performance da USP e fixar sua imagem (CARDOSO, 2001).

Essas mudanças ocorreram como elementos relativamente independentes entre si, ou, se quisermos, como medidas administrativas pontuais. Elas nunca foram explicitamente articuladas em um projeto geral de reforma universitária. No entanto, como uma medida pontual tende a levar à adoção de outras, as mudanças foram atingindo quase todas as instâncias, das tarefas administrativas mais rotineiras às mais altas estruturas de tomada de decisão.

Em uma de suas formas de implementação, a responsabilidade institucional foi interpretada pelos dirigentes da USP em sua dimensão social. Dada a enorme desigualdade educacional do país, essa face da terceira missão universitária corporifica-se em promoção do desenvolvimento social, com planos de abertura de vagas para a democratização do acesso ao ensino superior. A decisão de criar um programa de expansão de vagas em áreas vulneráveis da cidade, que resultou na USP-Leste, pode então ser vista como parte de uma mudança organizacional que conferiu um papel crucial para a responsabilidade social na USP.

Essa mudança foi introduzida na universidade por uma elite dirigente que está fortemente conectada com as instâncias de difusão das tendências acadêmicas globalizantes ${ }^{8}$. De fato, visitar centros de referência da educação superior moderna é uma tarefa essencial daqueles que estão no comando ${ }^{9}$. No exercício de

8 Em quase todas as nossas entrevistas com os líderes do projeto USP-Leste encontramos referências aos chamados "modelos modernos", notadamente à Universidade de Stanford. Dois dos coordenadores do projeto estavam recebendo professores de Stanford no dia da entrevista.

9 No caso específico aqui em pauta, no que se refere ao desenho pedagógico da USP-Leste, um membro 
funções e cargos de administração e direção, muitos professores universitários incorporam as tendências globais, interpretando-as e defendendo-as como um desejável processo de modernização.

Por que isso ocorre? Em parte, resulta do surgimento de um horizonte global de comparação e competição entre as universidades (KRÜCKEN; MEIER, 2006) que pressiona pela adoção das mesmas formas, práticas e discursos (POWELL; DIMAGGIO, 1991; HEDMO et al, 2006). Neste caso, porém, a conversão ao novo paradigma da gestão tem suas próprias raízes culturais.

Todos conhecemos as muitas análises da vida política brasileira que tratam do sentimento de atraso que perpassa a cultura nacional e alimenta a receptividade às tendências externas, vistas como modernas, desenvolvidas e avançadas. Isso é particularmente verdadeiro para as universidades, cujos líderes tendem a adotar rapidamente as orientações organizacionais globais, vistas como meios seguros de modernização (BOSI, 1992; CUNHA, 2004; DAGNINO, 2003; SANTOS, 1998). Esse traço cultural ajuda a entender o consenso em torno do projeto da USP-Leste: um novo significado organizacional transformou a velha reivindicação por equidade em um modo moderno e desejável de incluir a USP no espírito global da mudança acadêmica.

Esse significado aparece claramente na declaração da Coordenadora do projeto USP-Leste em reunião do Conselho Universitário para a aprovação da criação dos cursos em maio de 2004:

Hoje, estamos vivendo um momento dramático e, nesse tipo de cenário, o que propomos é que esse novo campus não seja apenas um processo de crescimento e aumento de vagas, mas seja, principalmente, um processo que permita a renovação da nossa Universidade. [...] [O] cenário universitário internacional [...] vive um momento em que as universidades buscam a renovação, formas de se modernizar e entender melhor as demandas do mundo contemporâneo. (Presidente da Comissão Central em Reunião do Conselho Universitário de 18 de maio de 2004)

Outro elemento da cultura política nacional que se liga ao conceito moderno de organização em nosso caso é o personalismo. Esse estilo muito difundido de liderança explica tanto a decisão do reitor como a do governador, a respeito do prazo para a implantação do projeto. Associado a estruturas de poder que o facilitam e promovem, ele permitiu que o reitor conduzisse a criação do campus no primeiro período neutralizando todas as formas de oposição.

da coordenação estudou experiências de ensino baseado em problemas, implantadas nos Estados Unidos, Canadá e Europa, em um processo de pesquisa que envolveu viagens pela Europa para visitar universidades e centros de ensino conhecidos pelo uso e desenvolvimento do modelo do PBL-Problem Based Learning. (Entrevista concedida em 21/10/10. Cf. também Arantes, 2005). 
Esse novo estilo de gestão e a tradicional centralização do poder de decisão na USP convergiram em uma configuração específica. A ideia da criação da USP-Leste como uma missão implicava controle estrito e coordenação forte. $\mathrm{O}$ controle estrito ligado à ideia de gestão competente permitiu dar um sentido moderno a padrões enraizados de centralização do poder e à tradicional concentração das estruturas institucionais decisórias. Desse modo, o que costumava ser visto como prática autoritária pode aparecer, nesse novo cenário, como gestão competente.

Além disso, um sentido ambivalente de urgência marcou a primeira fase do projeto, contribuindo para o ritmo acelerado da fundação. Como já dissemos, havia uma urgência dada pelo grau abissal das desigualdades de acesso ao ensino superior, que se manifestavam de forma dramática em São Paulo. Paralelamente, havia uma outra urgência dada por uma concepção de gestão moderna da universidade segundo a qual, por ser esta uma instituição financiada pelo Estado, era preciso "prestar contas" à sociedade, mostrando eficiência no uso de recursos. Essa eficiência, no caso da USP-Leste, viria pela abertura de vagas em cursos profissionalizantes, em uma região pobre da cidade, o mais rápido possível.

Esse duplo sentido de urgência - urgência social e administrativa - aproximou, em torno do projeto, dois grupos diferentes, por vezes opostos no espectro político da universidade: professores ligados à intelectualidade de esquerda, em geral, crítica da excessiva centralização universitária, e professores ligados à administração universitária que, ao contrário, enxergam nessa mesma centralização uma condição da eficiência executiva necessária à implantação de projetos controversos. Essa aproximação se expressa em declarações de que é preferível errar do que recair em suposto imobilismo, imposto seja pela temporalidade da reflexão, seja pela temporalidade dos conflitos, o que legitima a supressão de ambos:

O que me interessou, primeiro, foi ser [uma escola] na zona leste. Eu sou uma pessoa que tem toneladas de dúvidas sobre essas políticas de inserção, mas acho melhor errar do que não fazer nada. [...] Pode estar tudo errado, mas não dá para continuar sem fazer nada. (Membro de Comissão de Curso em entrevista concedida em 19/10/2010)

E nós tínhamos que tentar. Nós podemos errar, o que não podemos é ficar quietos. Podemos errar tentando e não errar sem tomar [decisões]. [Porque] essas discussões são muito demoradas. (Membro da Comissão Central em entrevista concedida em 28/10/2010) 
Certamente, o "erro" assume sentidos distintos para esses dois grupos, mas isso não impediu o acordo em torno da iniciativa, vista por uns como socialmente arrojada, por outros como institucionalmente modernizante.

A força dessa composição revela-se nas posições críticas ao projeto, que se expressaram na sessão do Conselho Universitário de maio de 2004. Incluída na pauta quando a construção da nova unidade já se encontrava em estágio avançado, faltando apenas alguns meses para o prazo estipulado pelo governador para o início das aulas, a proposta produz uma polarização entre algumas faculdades da USP, acompanhadas em peso pela bancada estudantil, e o resto do conselho, marcadamente pelos professores ligados à administração central.

A solicitação dos que rejeitavam a aprovação dos novos cursos era de que a votação fosse adiada para que as congregações, negligenciadas no processo, pudessem, também, apreciar o projeto, possibilitando, inclusive, que vários aspectos indefinidos na proposta pudessem ser esclarecidos. Ainda assim, ninguém ousou manifestar-se contra a criação da nova unidade da USP na zona leste de São Paulo:

Ressalto que nenhum de nós pode ser contra a instalação, ainda em 2005, dos cursos na Zona Leste. [...] peço que adiemos, de forma solidária, para não inviabilizar os cursos, para que eles estejam exatamente no cronograma previsto pela Reitoria, que tem que ser cumprido, mas que agitemos o local onde essas discussões têm que fluir que são as Congregações, no mínimo. (Professora da Faculdade de Educação, representante dos doutores)

Evidentemente, compartilhamos da ideia de que não se pode estar contra a expansão da Universidade pública e do número de vagas da universidade pública [...] [Mas] estamos preocupados com a pressa do início das atividades e perguntamos se essa prematuridade não estaria a serviço de interesses eleitorais, político-partidários. Estamos preocupados com a pressa da implantação e tememos que, em nome disso, se implante algo sem as bases sólidas necessárias. (Representante do Instituto de Psicologia)

Essa posição era compartilhada pela bancada estudantil que foi mais incisiva na crítica ao caráter centralizado do processo e à consequente incompletude do projeto:

[...] O modo como foi discutida a USP-Leste fere gravemente a autonomia universitária. A discussão desses cursos não passou por departamentos, congregações, e a única comissão que analisou questões como estrutura física da faculdade ou, por exemplo, a existência de ciclo básico, é composta inteiramente por pessoas indicadas pelo reitor. [...] Quero deixar bem clara a posição estudantil. Não somos contra a criação da USP-Leste. Somos contra o modo como foi discutido o calendário. (Representante discente da graduação) 
Tais posições deixaram aberto o espaço para as defesas da aprovação baseadas nos sentidos da urgência, argumentando que o Conselho Universitário deveria aprovar tais cursos imediatamente, correndo os riscos implicados tanto pela centralização excessiva, que efetivamente excluíra as instâncias intermediárias da discussão, quanto pela incompletude do projeto, que eles próprios reconheciam, em nome da responsabilidade social da universidade. $\mathrm{Na}$ formulação exemplar do diretor do Instituto de Química, que identifica a empreitada de risco com a perspectiva da transformação social:

Parto definindo o que, para mim, é conservadorismo. Em parte, conservadorismo é aquilo que reparo em uma série de posições colocadas, que é a extrema aversão ao risco. [...] 'Ensino superior para todos'é uma demanda social universal e que, aliás, é a recomendação de todos os documentos de organizações internacionais que pensam sobre isso. [...] Não tenho medo do risco. [...]

O reitor não acatou nem o pedido de vistas do processo, para que a discussão voltasse às congregações, nem a solicitação de que a votação fosse realizada com um quórum qualificado. Ambos inviabilizariam a aprovação dos cursos naquela reunião, o que comprometeria o início das aulas em 2005. O reitor negou tais pedidos alegando, justamente, a urgência social e administrativa do projeto, reiterando o compromisso com a comunidade da zona leste:

Lembro que há prazos e há a expectativa da sociedade de mil vagas. [...] É uma satisfação que está sendo dada à sociedade e que a expectativa já criada socialmente é de que essas vagas comecem em 2005. [...] Vamos votar simplesmente a criação dos cursos. Não é uma questão que mereça quórum qualificado. Foi feito um pedido de vistas que considero impossível e devemos partir para a votação, porque há um compromisso com a comunidade da zona leste, não com o governador. Evidentemente que recebemos dinheiro para construir o campus, implementar os cursos e se não forem aprovados, acabou. Não é uma questão de passar para o ano que vem, pois acaba o projeto USP-Leste. Vamos votar o parecer.

O resultado da votação foi a aprovação do parecer que instala os cursos da USP-Leste por 59 votos a favor, 9 contra e 14 abstenções, expressando o êxito produzido por uma convergência entre posições antagônicas tornada possível pela incorporação local de tendências transnacionais do campo universitário.

Nessa situação, o projeto da USP-Leste pode ser proposto como uma grande inovação, que renovaria toda a universidade, ao conquistar uma melhor inserção na sociedade contemporânea. Como afirmou claramente uma das coordenadoras do projeto na reunião de aprovação dos cursos da USP-Leste no Conselho 
Universitário da USP, em declaração já citada neste artigo, a USP-Leste aparece como um caminho a ser seguido por toda a USP no momento em, como todas as outras universidades, ela busca "se modernizar e entender melhor as demandas do mundo contemporâneo".

\subsection{Tensões e contradições entre mudança organizacional e especificidade institucional}

Quando o projeto se define como moderno, ele atribui uma perspectiva conservadora, tanto social como cultural, ao formato acadêmico tradicional. A universidade moderna também significa, assim, a universidade progressista, ligada aos valores da democracia, da igualdade social e do desenvolvimento nacional. Desse ponto de vista, a instituição acadêmica tradicional fica necessariamente comprometida com o elitismo cultural e os privilégios corporativos.

É essa disputa cultural que vai tomar nova forma em seguida, no âmbito das atividades cotidianas da escola, delineando o conflito entre os professores e os gestores no segundo período de implantação da USP-Leste, como portadores de concepções em profunda tensão entre si.

Um primeiro foco de conflito foi a concepção da estrutura institucional, sem departamentos. Até mesmo os professores em cargos de gestão na escola reconhecem a tensão entre as práticas acadêmicas de participação na tomada de decisão e a forma organizacional de coordenação que estava sendo praticada. Como expressou o chefe de gabinete e coordenador geral da USP-Leste:

Porque a universidade é um local onde se cultiva a diversidade de ideias, a diversidade de opiniões. A diversidade de opiniões [...] é que faz a universidade diferente. [...] Eu acho que isso tem que existir e espero que continue existindo sempre, porque, isso aqui, realmente, é um fator de estímulo para o desenvolvimento de uma instituição universitária. É que, num dado momento, do ponto de vista administrativo, a gente fica um pouco amarrado a essas coisas e aí dá um certo desconforto. Quando você tem posições, e são posições válidas, posições ideológicas e tudo, mas elas acabam gerando dificuldades muito grandes do ponto de vista operacional. Quer dizer, como conciliar esses interesses tão antagônicos? (Entrevista concedida em 08/10/2010)

A eliminação dos corpos deliberativos intermediários, feita em nome da agilidade administrativa, como um requisito da liderança moderna (MUSSELIN, 2006; BRUNSSON; SAHLIN-ANDERSON, 2000), acabou gerando grandes dificuldades para a administração. 
Eu até, às vezes, imagino: será que não seria mais fácil com departamentos? Porque tem a hierarquia. Tem mais clara a função de cada um. [] A gente vive algumas ambivalências porque, na sua essência, a comissão de curso é um colegiado pedagógico [ ]. Ela deveria se preocupar com questões pedagógicas e não administrativas, mas na ausência do departamento, fica um certo vácuo. (Coordenadora de curso em entrevista concedida em 30/09/2010)

[A ausência de departamentos deixou] um vácuo. [...] um vácuo administrativo. O papel administrativo de gestão que tem os departamentos vai cair todo em cima do diretor. Isso sim é uma dificuldade. E até agora não sei [como resolver]. Até então, não se discutia como que seria essa gerência. Então, agora, nós estamos reorganizando isso [...] e nós temos que fazer esse tipo de coisa, trocar a roda do carro andando, não dá para parar. (Diretor da USP-Leste em entrevista concedida em 28/09/2010)

De outra perspectiva, alguns professores interpretaram a ausência de departamentos como um modo ilegítimo de exclui-los das principais decisões da escola e, nesse sentido, o vácuo administrativo criou a impressão de uma falta de autoridade legítima na coordenação das atividades acadêmicas.

O que nós reclamávamos é assim: a instância decisória e executiva representada pelos conselhos de departamentos, ela vai ser substituída pelo quê? Nós vamos ficar com uma instância a menos de representação, discussão e ação. A Congregação vai formar todas as comissões, então, no fundo, ninguém vai ter a possibilidade de opinar sobre nada. A não ser que você consiga ser membro da Congregação, você vai estar fora de qualquer processo decisório importante. (Professor em entrevista concedida em 02/10/2010)

Uma resposta a esse vácuo foi a recriação informal de instâncias intermediárias de tomada de decisão, similares aos departamentos. As comissões de curso, originalmente concebidas para ter três professores, foram incorporando todos os membros do corpo docente, na maioria dos cursos.

Um segundo foco importante de conflito relaciona-se à dimensão pedagógica do projeto, em especial o currículo interdisciplinar e as novas pedagogias. Nela também se expressa a influência dos componentes do conceito de organização sobre as ideias e práticas dos criadores da USP-Leste. Uma vez definida como a mais distintiva contribuição inovadora do projeto, ela passou a ser apresentada como a própria identidade da escola. A consequência conflitiva foi que qualquer divergência era sentida pelos gestores como falta de cooperação com os objetivos institucionais, de modo que se opunha a identidade coletiva da instituição às iniciativas individuais dos professores. A ênfase na interdisicipli- 
naridade contribuiu para o enfraquecimento da independência dos professores. Mais ainda, o uso de técnicas de gestão de recursos humanos para coordenar processos de mudança organizacional fez com que sua formalização aparecesse como expressão da falta de competência especializada. O estilo organizacional de implementação foi considerado ofensivo pelos professores que não reconheciam o mérito acadêmico do projeto ou sentiam-se negligenciados em suas competências específicas.

Nesse mesmo registro, é possível explorar a disputa em torno do sentido do caráter autoritário da implementação do projeto. Para alguns docentes entrevistados para esta pesquisa, o autoritarismo caracterizava a coordenação do projeto, que pretendia centralizar e controlar decisões que cabiam, originalmente, aos professores:

Eu adorava a ideia, mas a gente pegou ódio porque era uma coisa tirânica. [...] Era abusivo, não pode chegar e dizer que eu tenho que dar tal coisa, que tem que dar aula assim, isso atinge os princípios básicos da universidade, é intolerável. [...] Então tinha uma dimensão pedagógica de mão pesada pra impor o modelo pedagógico; e tinha o autoritarismo, como não tinha estrutura, eles é que assinavam, eles que decidiam tudo, não tinha participação nenhuma [...] isso nos afastou do projeto. (Entrevista concedida em 24/08/2010)

Para outro professor entrevistado, o caráter autoritário, ou mesmo violento, residia na exigência de adesão total ao projeto:

Foi nesse momento que a interdisciplinaridade começou a aparecer para nós, mas ela começou a parecer para nós de maneira violenta. Ainda hoje gera em colegas meus um incômodo, esse termo. Porque nós sofremos um assédio de fato, não é? Foi um nível elevado de violência simbólica, você entrar no gabinete do reitor achando que ele vai falar umas palavras de encorajamento [...]. E, de repente, entramos lá e ouvimos que nós somos um problema, que nós estamos subvertendo as coisas, que a nossa proposta (para oferecer uma disciplina especifica) era um absurdo, que a gente era um grupo rebelde, que as nossas próprias contratações poderiam sofrer um revés se nós continuássemos assim... E dois dias depois, esse afastamento dos professores que também foi um afastamento que se deu em condições de bastante tensão. (Entrevista concedida em 02/10/2010)

No outro extremo, membros da coordenação central identificaram o caráter autoritário do processo justamente na falta de adesão, ou seja, na resistência e crítica de professores e coordenadores de curso, que inviabilizavam a realização do projeto no prazo estabelecido. Referindo-se ao mesmo afastamento de professores que a fala acima menciona, um dos coordenadores observa: 
Houve coordenador de curso substituído no primeiro dia de aula. [...] Porque eles estavam minando o projeto acadêmico e pedagógico. O que muitos acham autoritário e truculento - desculpa, eu faço parte da história - é a não adesão política, [por]que existe um projeto a ser implementado e ele só pode ser revisto depois que as pessoas souberem de fato o que é. [...] Então a reitoria tinha esse projeto muito claro. E foi dito: se você não concorda com esse projeto [...] então, que você não fique nele agora. (Entrevista concedida em 21/10/2010)

Vemos claramente como, no primeiro caso, a gestão centralizada que viabiliza a implementação do projeto em uma dada velocidade é interpretada na chave tradicional, como expressão do caráter autoritário da cultura e das instituições brasileiras que implementam projetos sem abrir espaço à participação e à crítica. No segundo, essa mesma centralização e velocidade são interpretadas como expressão de eficiência, ao passo que a resistência ou a contestação aparece como "autoritária" e "truculenta".

Finalmente, da perspectiva do trabalho docente, a coordenação do ensino inter e multidisciplinar e a ênfase nas pedagogias ativas baseadas em princípios gerais formalizados não pareceram eficientes. Foi somente quando as aulas começaram que os professores descobriram o descompasso entre seus estudantes e as definições dos requisitos do aprendizado ativo interdisciplinar. Eles tiveram que ajustar suas aulas, mudar conteúdos e formas de avaliação, o que foi trazendo de volta a independência e o caráter individual do ensino acadêmico, ao mesmo tempo que revelava a inadequação técnica da direção pedagógica central.

Dessa maneira, os conflitos entre o conceito de organização e a especificidade institucional foram sendo solucionados por aproximações às práticas e normas acadêmicas a partir daquele que identificamos como o terceiro período de implementação. Em termos gerais, ele se caracteriza como um momento de enfraquecimento da matriz organizacional de referência, quando a direção da escola abandona a ênfase em seu caráter de projeto-modelo de modernização, passando a ser vista como uma escola como todas as outras na universidade, como expressa claramente a mudança em sua designação - no início, como um novo campus inovador, ela era chamada de USP-Leste; atualmente ela tornou-se a EACH (Escola de Artes, Ciências e Humanidades), mais uma entre todas as unidades da USP, com suas históricas tensões que não impedem, ao contrário, possibilitam a produção científica e intelectual de excelecência da universidade mais tradicional do país. 


\section{CONCLUSÃO}

A ênfase organizacional da universidade, deslocada dos padrões tradicionais da profissão acadêmica foi, de fato, um obstáculo para o apoio do corpo docente à direção. Ao invés de promover a assimilação da identidade institucional, e suas missões e objetivos, o estilo organizacional centralizado tendeu a motivar o potencial defensivo das estruturas e práticas acadêmicas. Desse modo, o caso confirma que quando a mudança organizacional ignora as particularidades institucionais, ela provavelmente promove o seu próprio fracasso.

Consequentemente, o caso é exemplar das contradições geradas pela recusa das especificidades históricas e técnicas da universidade - precisamente porque consiste em uma realização extrema dessa recusa. A adesão explícita ou tácita dos dirigentes ao conceito de organização em um país como o Brasil pode, além disso, revelar o caráter contraditório do próprio conceito. Quando o ideal de organização colide com a tradição acadêmica, fica claro que seus componentes chocam-se internamente - aplicado ao engajamento social da universidade, o requisito organizacional do controle e da coordenação centralizados transforma-se em obstáculo ao principal objetivo da responsabilidade social, que é a promoção de maiores benefícios sociais.

Em termos mais gerais, o caso demonstra a necessidade de repensar o ideal da universidade como organização para alcançar um melhor entendimento e uma melhor promoção das chamadas funções sociais da academia. Acreditamos que a reflexão crítica sobre os referenciais teóricos das mudanças organizacionais em curso no ensino superior constitui uma contribuição importante para o debate atual sobre o papel institucional da universidade.

\section{REFERÊNCIAS}

ARANTES, Paulo Eduardo. Um departamento francês de ultramar.

Estudos sobre a formação da cultura filosófica uspiana. Rio de Janeiro: Paz e Terra, 1994.

ARANTES, Valeria Amorim. Articulação interdisciplinar entre conhecimentos científicos gerais: o ciclo básico da USP Leste. In: GOMES, Celso de Barros. (Org.). USP Leste. A expansão da Universidade de Oeste para Leste. São Paulo: Edusp, 2005. p. 101-118. 
BEN-DAVID, Joseph; ZLOCZOWER, Awraham. Universities and academic systems in modern society. European Journal of Sociology, Combridge, UK, v. 3, p. 45-84, 1962.

BLEIKLIE, Ivar; KOGAN, Maurice. Organization and governance of universities. Higher Education Policy, Paris, v. 20, p. 477-493, 2007.

BOSI, Alfredo. Dialética da colonização. São Paulo: Companhia das Letras, 1992.

BOURDIEU, Pierre. Meditações pascalianas. Rio de Janeiro: Bertrand Brasil, 2007.

BRUNSSON, Nils; SAHLIN-ANDERSSON, Kerstin. Constructing organizations. The example of public sector reform. Organization Studies, London, v. 21, n. 4, p. 21-46, 2000.

CANDIDO, Antonio. A revolução de 1930 e a cultura. Novos Estudos, São Paulo, v. 2, n. 4, p. 27-36, abr. 1984.

CARDOSO, Irene. A universidade da comunhão paulista. São Paulo: Cortez, 1982.

. Para uma crítica do presente. São Paulo: Editora 34, 2001.

COHEN, Michael D. et al. A garbage can model of organizational choice. Administrative Science Quarterly, Thousand Oaks, v. 17, n. 1, p. 1-25, 1972.

COMIN, Alvaro. Mudança na estrutura ocupacional do mercado de trabalho em São Paulo. 2003. Tese (Doutorado em Sociologia) - Faculdade de Filosofia, Letras e Ciências Humanas, Universidade de São Paulo, São Paulo, 2003.

CONSELHO DE REITORES DAS UNIVERSIDADES ESTADUAIS DE SÃO PAULO. Expansão do sistema público superior. São Paulo: CRUESP, 2001.

CUNHA, Luis Antonio. A universidade reformada. São Paulo: Editora Unesp, 2004.

DAGNINO, Renato. A relação universidade-empresa no Brasil e o "argumento da hélice tripla". Revista Brasileira de Inovação, Campinas, v. 2, n. 2, p. 267-307, jul./dez., 2003. 
DRORI, Gili S. et al (Eds.). Globalization and organization. Oxford: Oxford University Press, 2006.

FRANK, David J.; MEYER, John W. University expansion and the knowledge society. Theory and Society, Germantown, NY, n. 36, p. 287$311,2007$.

GOMES, Celso de Barros. (Org.). USP-Leste. A expansão da universidade do oeste para o leste. São Paulo: Edusp, 2005.

GUIMARÃES, Antônio Sérgio. Classes, raças e democracia. São Paulo: Editora 34, 2002.

. Acesso de negros às universidades públicas. Cadernos de Pesquisa, São Paulo, n. 118, p. 247-268, 2003.

HEDMO,Tina et al. Is a organizational field of higher education emerging? Management education as an early example. In: KRÜCKEN, Georg et al. (Eds.). Towards a multiversity? Universities between global trends and national traditions. Bielefeld: Transcript Velag, 2006.

KRASILCHIK, Myriam. USP Leste: sonho e realidade. In: GOMES, Celso de Barros. (Org.). USP-Leste. A expansão da universidade de oeste para leste. São Paulo: Edusp, 2005.

. Gestão: desafios e perspectivas. Revista USP, São Paulo, n. 78, p. 22-31, 2008.

KRÜCKEN, Georg; MEIER, Frank. Turning the university into an organizational actor. In: DRORI, Gili S. et al. (Eds.). Globalization and organization. Oxford: Oxford University Press, 2006.

KRÜCKEN, Georg et al. (Eds.). Towards a multiversity? Universities between global trends and national traditions. Bielefeld: Transcript Velag, 2006.

MEYER, John W. et al. (2006). Conclusion. In: DRORI, Gili S. et al. (Eds.). Globalization and organization. Oxford: Oxford University Press, 2006. p. 258-274.

MICELI, Sergio. Condicionantes do desenvolvimento das ciências sociais no Brasil, 1930-1964. Revista Brasileira de Ciências Sociais, São Paulo, v. 2, n. 1, p. 5-26, 1987. 
MUSSELIN, Christine. Are universities specific organizations? In: KRÜCKEN, Georg et al. (Eds.). Towards a multiversity? Universities between global trends and national traditions. Bielefeld: Transcript Velag, 2006.

OLIVEIRA, Francisco de. Crítica à razão dualista. São Paulo: Boitempo, 2003.

POWELL, Walter W.; DIMAGGIO, Paul J. (Eds.). The new institutionalism in organizational analysis. Chicago: The University of Chicago Press, 1991.

SANTOS, Laymert Garcia dos. Tecnologia, natureza e a "redescoberta" do Brasil. In: ARAUJO, Hermetes R. de. (Ed.). Tecnociência e cultura. São Paulo: Estação Liberdade, 1998.

SÃO PAULO. Olhar São Paulo. Contrastes urbanos. São Paulo: Secretaria Municipal de Planejamento, 2007.

SCHWARTZMAN, Simon. Brazil's leading university: between intelligentsia, world standards and social inclusion. In: ALTBACH, Philip G.; BALÁN, Jorge (Eds.). World class worldwide. Transforming research universities in Asia and Latin America. Baltimore: The Johns Hopkins University Press, 2007.

SILVA, Franklin Leopoldo e. A experiência universitária entre dois liberalismos. Tempo Social, São Paulo, v. 11, n. 1, p. 1-47, 1999.

SILVA, Alberto Carvalho. Descentralização em política de ciência e tecnologia. Estudos Avançados, São Paulo, v. 14, p. 61-73, 2000. 